\title{
Mediating Effect of Risk Management Practices on the Relationship between Owner's Risk Attitude and Business Performance of Small and Medium Enterprises: Evidence from North Central Province of Sri Lanka
}

\author{
Bandara, D ${ }^{1}$ and Ekanayake, $A^{2}$ \\ ${ }^{1}$ Rajarata University of Sri Lanka, ${ }^{2}$ University of Peradeniya
}

\begin{abstract}
Small and Medium Scale Enterprises (SMEs) are known as an important strategic sector which has the potential to contribute towards GDP, employment generation, poverty alleviation and regional development particularly in the developing countries such as Sri Lanka. However, the main issue of SMEs is poor business performance that affects adversely their survival in the long run. Among other reasons, poor risk management practices have been identified as a main cause for such failures. Although risk taking is a fundamental for business performance, not managing the former properly will have an adverse impact on the latter. Therefore, this study aims to investigate the mediating impact of risk management on the relationship between owner's risk attitude and business performance. The study was a basic explanatory type quantitative examination that followed the deductive reasoning method. A conceptual framework has been developed based on the literature survey that provided the basis for empirical investigation. Out of the SMEs established in the North Central Province of Sri Lanka, 200 SMEs have been selected as the sample of the study following the random sampling procedure. Data were collected on researcher-administrated questionnaires and were analyzed using SPSS statistical package. As per the stepwise regression analysis, it was found that risk management practices of SMEs mediate the relationship exists between the owner's risk attitude and business performance. Based on the findings, the study recommends that owners of SMEs should implement appropriate risk management practices in their SMEs while government institutions related to the SME sector should provide them with necessary support to establish proper risk management practices in their organizations.
\end{abstract}

Keywords: owner's risk attitude, risk management practices, business performance, small and medium enterprises 


\section{Introduction}

Small and Medium Scale Enterprise (SMEs) sector has become a vital section of private sector particularly in developing countries such as Sri Lanka, as they have gained a wide recognition being a major source of employment, income generation, poverty alleviation and regional development. Also, SMEs have been identified as an important strategic sector for promoting economic growth and social development in Sri Lanka (Kalegama, 2002). For instance, according to Jayasekara and Thilakarathne (2013), SMEs play a significant role in economic development through creating employment opportunities, mobilizing domestic savings, poverty alleviation, income distribution, regional development, training of workers and entrepreneurs, creating an environment in which large firms flourish and contributing to export earnings in Sri Lanka.

Even though the potential roles of SME sector towards the Sri Lankan economy is substantial, most of the SMEs suffer from managerial problems specially pertaining to risk management aspect that ultimately leads to poor business performance and going concern issues. Jayathilake (2012) has identified that: (a) management of risk in SMEs is strongly concentrated on owner managers, and (b) the risk management practices are not well developed in SMEs. It appears that the attitudes of the owner managers and their knowledge towards risk play an essential role in how risks are managed systematically in the SMEs.

This situation seems to be common in the international arena as well. For instance, Idemobi (2012) reports that 70 percent of SMEs die within five years of establishment due to management problems specially pertaining to risk management.
This claim is also confirmed by the study of Yusuf and Dansu (2013), which reveals that many of the SMEs have failed not only due to results from basic challenges, but also due to the poor attitudes of SMEs owners towards business risk and how they are managed. Further, this study emphasizes that managerial decisions of SMEs are usually at the mercy of the key owner who more often lacks basic managerial skills, qualities and culture to manage a business successfully. Despite the issue of poor risk management in SMEs both locally and internationally, there is a dearth of research that has been conducted during the past which has created an empirical research gap in this study area. In particular, statistical generalizations are not available to measure how risk management practices of SMEs impact on business performance in Sri Lanka as well as in the rest of the world. Hence, it is important to investigate the relationship between owner's risk attitude and business performance of SMEs, and the mediatory impact of risk management on the relationship between owner's risk attitude and business performance of SMEs in Sri Lanka.

The study is confined to the SMEs established in North Central Province of Sri Lanka due to the particular importance of SME sector to that province for economic development, employment generation and poverty elevation. It is apparent that level of economic development, availability of human resources, advancement of technology, and existence of infrastructure facilities among the provinces in Sri Lanka are significantly different. Such differences lead to create heterogeneity of SMEs on risk management and business performance among the provinces, and therefore, conducting a study covering the whole 
island may not yield generalizable findings.

\section{Problem statement}

A number of studies conducted in the past confirm the importance of enhancing business performance of SMEs and ensuring sustainability of SMEs towards the economic development of a country. Even though SME sector in Sri Lanka has many opportunities to contribute to the economic development, they tend to fail in reality particularly due to the problems encountered in managing the risks. For example, Abeyrathna and Kalainathan (2016) revealed that although SMEs in Sri Lanka implement different risk management practices up to a certain extent, the quality of those risk management practices is still in a poor level. The reason behind this would be the unawareness of owner managers about the risk management practices, or it may also be due to the unavailability of large amount of funds for SMEs to invest in upgrading the quality of risk management practices like large enterprises do. SMEs face number of operational risks and managing those risks may not happen due to the above reasons. Given that businesses are managed solely by the owner who makes decisions often without having adequate managerial skills, qualities and culture to manage a business successfully. In addition, a high employee turnover of SMEs is likely to create a poor and unstable organization structure (Yusuf and Dansu, 2013).

Poor business performance in the SME sector has remained unexplained for a long time especially in the developing countries where the SMEs occupy the large part of the economy (Brigham, 2002). Thrikawala (2011) studied networking of SMEs in Sri Lanka and its impact on the development of SMEs. Networking can be considered as one of the risk management practices employed by SMEs for their long term development and sustainability. In consistent with the earlier proposition, this study reveals that a little attention has been given on networking like in the other developing countries. On the other hand, Falkner and Hiebl (2015) claim that risk management practices in SMEs have been increased in recent years but still there is no systematic review was conducted on this topic. Also, risk management in SMEs has not received desired attention in the literature despite its importance. For instance, Henschel (2009) submits that there are very few sources in the literature on risk management practices of SMEs. This indicates that still risk management of SMEs is in the development phase therefore further studies are required in this research area to fill this existing research gap.

The nature of risk management practices of SMEs has been investigated internationally (e.g., Yusuf and Dansu,2013;Smit and Watkins, 2012;Luper and Isaa, 2012;Mansor, et al., 2016; Ahmed and Manab, 2016) as well as locally (e.g., Jayathilake, 2012; Abeyrathna and Kalainathan, 2016; Rathnasiri, 2015). These studies found that owner plays a significant role in the risk management of SMEs. However, even though such literature investigate the impact of owner's risk attitude on business performance, mediating impact of risk management practices on the relationship between owner's risk attitude and business performance has not been studied. In other words, there is no any statistical justification available in the literature to analyze the mediating impact of risk management function in SMEs. Therefore, the current study aims to fulfill 
this research gap by examining the impact of owner's risk attitudes on business performance of SMEs and mediatory impact of risk management on this relationship.

\section{Research objectives}

In order to address the research problem as discussed in the previous section, following objectives have been set:

i. To investigate whether owner's risk attitude positively impact on business performance of SMEs in North Central Province of Sri Lanka.

ii. To investigate whether risk management practices of SMEs mediate the relationship between owner's risk attitude and business performance of SMEs in North Central Province of Sri Lanka.

\section{Literature review}

Despite being discussed extensively in the literature, there is no universally accepted definition for SMEs (Henschel, 2009). This may be because there are no uniform criteria to measure them, for example, in terms of capital outlay, number of employees, sales turnover, fixed capital investment, available plant and machinery, market share and/or level of development. Similarly in Sri Lanka, there is no a common definition identified for SMEs. The non-existence of a nationally accepted definition and clear cut criteria create problems in identifying SMEs population in Sri Lanka preciously (Thrikawala,2011). However, it is worthwhile to explore the existing literature to identify a suitable definition or a criterion for SMEs to match with the objectives of the current study and to carryout a legitimate investigation.

The current study investigates mainly the impact of risk management practices of SMEs on the relationship between owner's risk attitude and business performance. In SMEs, success of the risk management practices depends largely on the owner's perception towards risk and formation of risk management practices within the organization, as well as employees skills in implementating those risk management practices (Yusuf and Dansu, 2013; Turpin, 2002; Henschel, 2009). Thus, the responsibility of risk management goes to owner's and employees' account. Also, previous studies used number of employees as one of the criteria to define SMEs in Sri Lanka. Given that number of employees shows the extent of work delegation of the organization, it can be used to investigate the impact of risk management practices on the business perofrmance of SMEs.

The existing literature suggets that the risk management function in SMEs is to a larger extent depended on the owner managers. For instance, Watt (2007) opines that risk management of SMEs will greatly be influenced by the owner's risk perception and their attitude towards risk management. Further, Yusuf and Dansu (2013) claim that risk management of SMEs are basically the responsibility of the owner who will account for the decisions made to the business. Furthermore, Turpin (2002) states that most of SMEs do not have official risk management strategy due to the problems of communication with delegating risk management competencies to employees. Finally, Henschel (2009) elaborates that risk management is a challenge for SMEs in contrast to larger firms as they often lack of the necessary resources, such as human capital, data base and specificity of knowledge, to perform a standard and structured risk management. 
Most of the researchers agree that risk management in an organization is a formal process which is used to achieve organizational objectives. For example, Head (2009) defines risk management as a process of planning, organizing, directing and controlling resources to achieve given objectives when good or bad events are possible. Risk management can be defined as an ongoing process that can help to improve operations, identify priorities and resources, ensure regulatory compliance, achieve performance targets, improve financial stability and ultimately prevent loss and damage to the entity (Dickinson, 2001). Similarly, Raghavan and Sayeed (2005) argue that risk management is an ongoing process targeted to enhance operation, practices, and resource allocation, ensure compliances to establish rules, achieve performance goals, improve financial health and prevent damage to the firm. Moreover, Smit and Watkins (2012) define risks management as a process that consists of risk identification, risk evaluation, risk mitigation and risk monitoring. Accordingly, these steps of risk management process mean that entrepreneurial or management of SMEs should focus on recognizing future uncertainty, deliberating risks, possible manifestations and effects, and set plans to address these risks and reduce or eliminate its impact on the enterprise. Further, continuous reviewing of risk management process and making alteration on risk assessment and risk mitigation strategies are required.

It is worthwhile to examine the risk management practices of SMEs in particular given the aim of this study. According to Yusuf and Dansu (2013), SME's risk management is basically the responsibility of the owner, who will account for risk decisions made for the business. Also, Watt (2007) opines that the risk management function in SMEs is usually at the prerogative of the owner. These claims suggest that risk management practices of SMEs will greatly be influenced by the owner's risk perception and their attitude towards risk management. Such claims suggest that attitude of SMEs towards risk and their assessment differs significantly from large enterprises (Gwangwava et al., 2014). That is risk management practices in SMEs relate to the beliefs and attitudes of owners. For example, Abeyrathna and Kalainathan (2016) noted that owner of a SME is often a part of the management team and their intuition and experience are important for managing the firm. All in all it can be concluded that risk management practices of SMEs are greatly influenced by owner's risk attitude.

Blais and Weber (2006) define risk attitude as a broad description of the way the decision maker deals with risk, and classify it into two: risk propensity and risk perception. Sitkin and Pablo (1992) define risk propensity as the entrepreneur's general likelihood of behaving more or less in a risky manner and how entrepreneurs evaluate the risk-return trade-off. Further, risk perception is defined as "a decision maker's assessment of the risk inherent in a situation".Boermans and Willebrands (2017) have also identified risk propensity and risk perception as the two key dimensions of the owner's risk attitude, and further emphasized that owner's risk attitude has a significant impact on business performance of SMEs.

Firm performance is one of the most important variables that attracted the attention of researchers in both finance and 
management literature (Gavrea, et al., 2011). Business performance can also be identified as a key variable that decides the going concern of SMEs. Most of the researches agree that business performance of an organization refers the firm's ability to achieve its goal through the application of available resources in an efficient and effective manner (Ahmed and Manab, 2016; Antony and Bhattacharyya, 2010; Asat, et al., 2015; Smith and Reece, 1999). Business performance can be measured both objectively (e.g., profit figure, return on asset, return on investment) and subjectively (e.g., five points or seven points Likert scale performance criteria in empirical researches). Most researchers prefer subjective measures above the objective measures in assessing the performance of SMEs due to reasons such as unavailability of financial data, manipulation of available financial data and difficulties in obtaining standard financial data (Zulkiffli and Perera, 2011; Dess and Robinson,1984; Wall, et al., 2004). For example, Zulkiffli and Perera (2011) proposed that market performance, supplier performance, process performance, people performance and customer relationship performance are appropriate subjective measures.

Market performance of SMEs covers basically market share growth and growth of sales or turnover. Further, supplier performance measures supplier product quality, supplier communication and supplier delivery performance while process performance of SMEs covers work in process, complete of customer order on time and development of product quality. Furthermore, people performance means performance appraisal of employees, skill level of employees and communication skills. Finally, customer relationship performance covers resolution of customer complaints, customer loyalty or retention, quality reputation and award achievement, product returns rate, and the speed of order handling and processing.

The above discussion on owners risk attitude, risk management practices and business performance of SMEs leads to the development of the conceptual framework set out in Figure 1. Also, based on the relationships identified in the conceptual framework, following two hypotheses have been developed for empirical investigation.

$\mathrm{H}_{1}$ : Owner's risk attitude positively impact on business performance of SMEs in North Central Province of Sri Lanka.

$\mathrm{H}_{2}$ : Risk management practices mediate the relationship between owner's risk attitude and business performance of SMEs in North Central Province of Sri Lanka.

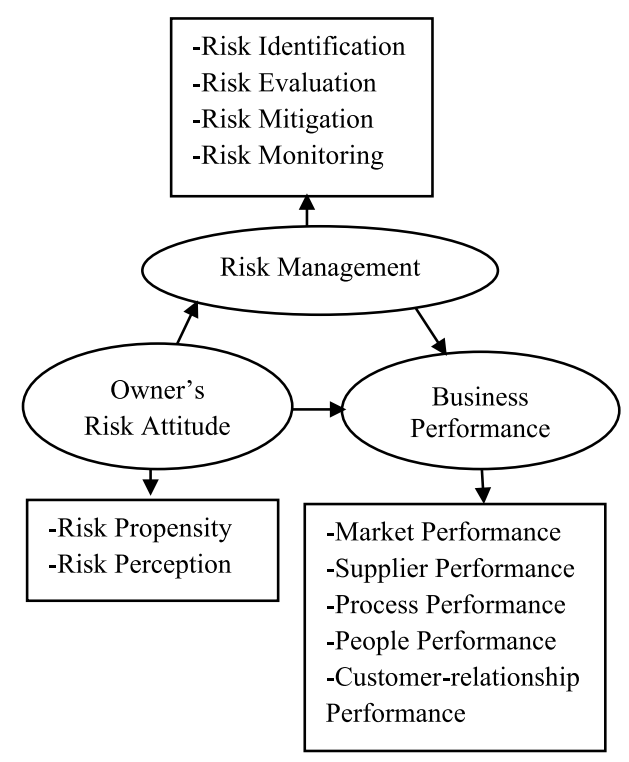

Figure 1: Conceptual framework

\section{Methodology}

This study has been undertaken to examine the mediating impact of risk management 
practices on the relationship between owner's risk attitude and business performance of SMEs in Sri Lanka with a special reference to the North Central Province. Hence, type of the study was applied research or explanatory research in nature. The population of the study is SMEs in the North Central Province of Sri Lanka which includes sole proprietorships, partnerships and private limited companies. The owner of SMEs is identified as the unit of analysis. Determining a clear cut numbers of population of SMEs in Sri Lanka or in the North Central Province is imprecise due to inaccuracy of all available databases and also due to the fact that different governmental institutions define SMEs in terms of different criteria (Rathnasiri, 2015). Therefore, the study selected 200 SMEs as the sample following random sampling method covering both Anuradhapura and Polonnaruwa districts of the North Central Province of Sri Lanka. However, 140 firms have been taken into the final data analysis due to non-respondents and eliminating outliers.

According to the developed conceptual framework based on the literature survey, owner's risk attitude was the independent variable while business performance positioned as the dependent variable. The conceptual framework also shows risk management practices of SMEs as the mediating variable of the study. Operationalization of these variables has been planned in such a way to ensure right variables were fitted into the model, respective definitions and dimensions were recognized, and correct indicators have been developed to convert variables from psychological domain to analytical domain based on the findings of the past literature (Blais and Weber, 2006; Boermans and
Willebrands, 2017; Sitkin and Pablo,1992; Head, 2009; Dickinson, 2001;Smit and Watkins,2012; Ntlhane, 1995; Labodova, 2004; Ahmed and Manab, 2016; Antony and Bhattacharyya, 2010; Asat et al., 2015; Zulkiffli and Perera, 2011; and Dess and Robinson, 1984).

The researcher administrated close ended questionnaire based on a five point Likert scale to measure the independent, dependent and mediating variables has been used to gather data. A pilot survey was carried out to refine the questionnaire by distributing questionnaires among 48 SMEs in the Anuradhapura district and 36 SME owners have been responded. Based on such responses, the required amendments have been done to refine the questionnaire. Reliability of data was tested in accordance with Cronbach's alpha Test which reported the value more than 0.7 for all dimensions, except supplier performance and process performance which reported a value of more than 0.6. Thus, reliability of all dimensions employed is at an acceptable level. Further, validity of the questionnaires was tested, and convergent and discriminate validity were confirmed by the results. The former validity was tested among dimensions to each variable, and the component extracted values of all the dimensions were greater than acceptable level (i.e., 0.6) (Chawla and Sondhi, 2016) while Kaiser - Meyaer - Olkin (KMO) value was above the level of 0.5 .Further,latter type of validity was tested in SPSS software by the confirmatory factor analysis. Dimensions have been loaded under seven variables, resulting risk attitude and risk management was truly distinct from each other. The dimension of supplier performance would have been loaded under the business performance but it was neither loaded under that variable nor does it 
generate any value. Hence, the dimension of supplier performance has been removed from further analysis in order to arrive at more accurate results of the study.

The study employed various kinds of statistical tests, namely normal probability plot was used to test whether data set is approximately normally distributed, VIF value was used to test whether multicollinearity exist between independent variables, Pearson Correlation Test was used to test the degree of association between independent and dependent variables, while at the end step wise regression analysis has been used to test the hypotheses developed in the study.

\section{Results of the Study}

Table 1 show results of the correlation analysis employed which confirms that correlation coefficient of the owner's risk attitude (RA) and risk management (RM) was 0.202 and 0.556 , respectively. Both these correlation coefficients were statistically significant at 0.05 percent level. This indicates that owner's risk attitude, risk management and business performance (BP) in SMEs are positive associated.

Table 1: correlation analysis

\begin{tabular}{|l|c|c|c|}
\hline Variables & BP & RA & R/M \\
\hline BP & 1.000 & & \\
RA & $0.202^{*}$ & 1.000 & \\
RM & $0.556^{* *}$ & 0.125 & 1.000 \\
\hline
\end{tabular}

* Correlation is significant at the 0.05 level (2tailed).

Source: survey data, 2019

Table 2, 3 and 4 indicate the results of step wise regression test. According to Table 2, two separate models have been developed in the regression analysis to explain the impact of the owner's risk attitude on business performance of SMEs and the mediating impact of risk management on the relationship between owner's risk attitude and business performance of SMEs.

According to Table 2, "R Square" of the model one was 0.041 . It indicated that when other factors are constant, 4.1 percent variation of business performance was explained by the owner's risk attitude. Further, as per Table 2, "R Square" of the model two was 0.327 which indicated that when other variables are constant, 32.7 percent variation of business performance is explained by both variables of owner's risk attitude and risk management. According to the model two, "R Square" value change was $0.286(32.7-4.1)$. Thus, it implies that 28.6 percent variation of business performance is explained by risk management out of 32.7 percent total variation of business performance.

Table 2: model summery

\begin{tabular}{|l|l|l|l|}
\hline Model & $\mathrm{R}$ & R Square & $\begin{array}{c}\text { R Square } \\
\text { Change }\end{array}$ \\
\hline 1 & $0.202^{\mathrm{a}}$ & 0.041 & 0.041 \\
2 & $0.572^{\mathrm{b}}$ & 0.327 & 0.286 \\
\hline
\end{tabular}

a. Predictors: (Constant), Owner's Risk Attitude

b. Predictors: (Constant), Owner's Risk Attitude, Risk Management

c. Dependent Variable: Business

Performance

Source: survey data, 2019

According to Table 3, the 'significant' value of ANOVA test was 0.017 at first step and 0.000 at the second step. It was less than the standard level (0.05) which indicates that regression coefficients of owner's risk attitude and risk management were not equal to zero. Hence, model is strong enough to predict the linear relationship among independent variable, mediating variable and dependent variable. 
Table 3: ANOVA table

\begin{tabular}{|l|c|c|}
\hline \multicolumn{1}{|c|}{ Model } & F & Sig. \\
\hline $\begin{array}{l}\text { 1 Regression } \\
\text { Residual Total } \\
\text { 2 Regression } \\
\text { Residual Total }\end{array}$ & 5.840 & $.017^{\mathrm{b}}$ \\
& 33.247 & $.000^{\mathrm{c}}$ \\
\hline
\end{tabular}

a. Dependent Variable: Business

Performance

b. Predictors: (Constant), Owner's Risk

Attitude

c. Predictors: (Constant), Owner's Risk

Attitude, Risk Management

Source: survey data, 2019

The hypotheses developed in the study have been tested based on stepwise regression as follows.

$\mathrm{H}_{1}$ : Owner's risk attitude of SMEs positively impacts on business performance of SMEs of North Central Province in Sri Lanka

According to model one in Table 4, regression coefficient of the owner's risk attitude is 0.202 . The significant value of the test was 0.017 which was below the standard level (0.05). Hence, the positive impact of the owner's risk attitude on the business performance of SMEs was statistically significant at 0.05 percent level. Therefore, the study accepts $\mathrm{H}_{1}$ : Owner's risk attitude of SMEs positively impacts on business performance of SMEs of North Central Province in Sri Lanka.

$\mathrm{H}_{2}$ : Risk management of SMEs mediates the relationship between owner's risk attitude and business performance of SMEs in North Central Province in Sri Lanka.

According to model two in Table 4, regression coefficient of the owner's risk attitude was 0.134 . The significant value of the test was 0.060 which was above the standard level (0.05). Hence, the positive impact of the owner's risk attitude on the business performance of SMEs was become statistically insignificant at 0.05 percent level. Also, regression coefficient of the owner's risk attitude has come down from 0.202 to 0.134 . Moreover, regression coefficient of the risk management was 0.539 while the significant value of the test was 0.000 which was above the standard level (0.05). Therefore, at the model two, the impact of owner's risk attitude has become statistically insignificant while the impact of risk management has become statistically significant at 0.05 levels. Thus, study accepted $\mathrm{H}_{2}$ : risk management of SMEs mediates the relationship between owner's risk attitude and business performance of SMEs of North Central Province in Sri Lanka.

Table 4: regression coefficient table

\begin{tabular}{|l|c|c|}
\hline \multicolumn{1}{|c|}{ Model } & $\begin{array}{c}\text { Standardized } \\
\text { Coefficients (Beta) }\end{array}$ & Sig. \\
\hline 1 RA & .202 & .000 \\
2 RA & .134 & .060 \\
2 RM & .539 & .000 \\
\hline
\end{tabular}

Dependent Variable: Business Performance

Source: survey data, 2019

\section{Discussion}

As presented in the previous section, regression analysis results indicated a statistically significant positive impact of owners risk attitude on business performance of SMEs of North Central Province in Sri Lanka. This finding of the study is in consistent with the results of studies (Boermans and Willebrands, 2017; Adeyele and Omorokunwa, 2017; Hormiga and Bolivar-Cruz, 2014; andWillebrands, et al.,2012). In particular, Boermans and Willebrands (2017) found that owner's risk attitude is significantly positively associated with business 
performance of SMEs. On the other hand, several studies, such as Naldi, et al. (2007), Tang and Tang (2007), Tang, et al. (2010), Lechner and Gudmundsson (2014) and Robinson and Marino (2013), found that owner's risk attitude has a negative impact on business performance of SMEs. Furthermore, Thapa (2015) found that there is no any significant impact of owner's risk attitude on business performance.

According to Table 4, the step-wise regression results of the study, regression coefficient of the owner's risk attitude was 0.134 while significant value of the test was 0.060 . This indicates that the positive impact of owner's risk attitude on business performance has become statistically insignificant. On the other hand, regression coefficient of the risk management was 0.539 and the significant value of the test was 0.000 . This signals that the variable risk management function mediates the relationship between owner's risk attitude and business performance at a statistically significant level. These findings are in consistent with the studies (Boermans and Willebrands, 2017; Adeyele and Omorokunwa, 2017; Hormiga and BolivarCruz, 2014; and Willebrands, et al., 2012). Moreover, it was found that risk management function is greatly influenced by owner's risk attitude. This finding was aligned with the findings of previous studies (Sparrow, 1999; Ntlhane, 1995;Dickinson, 2001; Watt, 2007;Jayathilake, 2012;Smit and Watkins, 2012). Furthermore, it was found that business performance of SMEs was influenced by risk management function, and this finding was agreed with the findings of previous studies (Vaughan and Vaughan, 2001; Yusuf and Dansu, 2013;Bayaga, et al., 2013;Kagawathi, et al., 2014; and Abeyrathna and Kalainathan,
2016).As discussed in the literature review section, findings of all these studies emphasize that risk management function of SMEs mediate the relationship between owner's risk attitude and business performance. But, this argument was not statistically justified in any of the previous studies. For instance, there was no model which has been developed to test the mediating effect of risk management in the previous studies. As discussed previously, hypothesis 2 confirms that there is a mediating impact of risk management on the relationship between owner's risk attitude and business performance. Therefore, findings of this study filled this gap in the existing literature.

\section{Conclusion and Implications}

The stepwise regression analysis explained the way in which owner's risk attitude and risk management of SMEs impact on their business performance. The findings of the study are consistent with many of the previous studies as discussed in the literature review section. Even though there is a close positive relationship between owner's risk attitude and business performance, risk attitude does not necessarily improve the business performance always. But, it depends on the risk management practices adopted by the SMEs.

The study explained the impact of owner's risk attitude on business performance of SMEs and the mediating impact of risk management on this relationship based on the model developed in this study following the literature survey. Hence, the model contributes to the general body of knowledge about risk management of SMEs and serves as a framework for future studies in the SME sector. Furthermore, this study has identified 
research gaps in the existing literature such as unexplained reasons for poor business performance in the SME sector, lack of attention given on examining risk management practices of SMEs, and dearth of literature on a systematic review of risk management in SMEs. The current study examined owner's risk attitude, risk management and business performance together to analyze the mediating impact of risk management practices of SMEs on the relationship between owner's risk attitude and business performance. Therefore, this study contributed to fill those existing research gaps and existing knowledge about SMEs particularly in the developing country perspective.

The findings of the study have both managerial and policy implications. The results indicate the importance of establishing and implementing risk management practices within the SMEs. For this purpose, they may use the Check List which has been developed based on the instruments used in this study (See Appendix 1). This checklist can be used to evaluate how well risk is managed by SMEs and owners of SMEs can take suitable actions to develop and implement risk management practices for lapses areas with the application of the Check List.

Further, the finding of this study will be useful for policy makers who can use the findings and the Check List to assist SMEs in developing and implementing proper risk management practices in their organizations. For instance, training programs can be arranged to enhance knowledge and awareness of the owners among the SMEs with an aim to improve risks management practices in those organizations.

However, this study was limited to the SMEs in the North Central Province of Sri Lanka and only 200 SMEs have been selected as the sample due to the constrains, such as time, cost and lack of research culture in Sri Lanka. Therefore, findings of the study may not be generalizable to all the SMEs in Sri Lanka. For example, there can be differences related to knowledge and awareness among the owners of SMEs about the risk management practices, and the entrepreneurial and technological support available in the provinces. Further, the study was able to complete 140 questionnaires out of the 200 sample size due to the reasons such as lack of data availability and incomplete questionnaires. This might have adversely affected in the final data analysis. Future studies can be conducted in other provinces of Sri Lanka or considering the entire country as the population. Such studies may provide further evidence on the effectiveness of risk management practices and the business performance of the SMEs within the Sri Lankan context.

\section{References:}

Abeyrathna, G. M., \& Kalainathan, K. (2016). Financial risk, financial risk management practices and performance of Sri Lankan SMEs: special reference to Anuradhapura district. Research Journal of Finance and Accounting,7(15), 16-22.

Adeyele, J. S., \& Omorokunwa, O. G. (2017). Risk appetites and empirical survival pattern of small and medium enterprises in Nigeria. The Journal of Entrepreneurial Finance,18(2), 7375.

Ahmed, I., \& Manab, N. A. (2016). Influence of enterprise risk management success factors on firm financial and non-financial performance: a proposed model. 
International Journal of Economics and Financial Issues, 6(3), 830-836.

Antony, J. P., \& Bhattacharyya, S. (2010). Mearsuring organizational performance and organizational excellence of SMEs part 2: an empirical study on SMEs in India. Me asuring Business Excellence, 14(3), 42-52.

Asat, S. H., Maruhun, E. N., Haron, H., \& Jaafar, M. (2015). Enterprise risk man a gement (ERM) and organizational performance: The case of housing developers in Malaysia. MARIM International Conference. Langkawi.

Bayaga, A., Flowerday, S., \& Piderit, R. (2013). ICT operational risk management (ORM) and performance of a financial SME. The Pakistan Development Review,52(2), 127-138.

Blais, A., \& Weber, E. (2006). A domainspecific risk-taking (DOSPERT) scale for adult populations. Judgment and Decision Making,1(1), 33-47.

Boermans, M., \& Willebrands, D. (2017). Entrepreneurship, risk perception and firm performance. Discussion Paper Series, 17(04). Landen: Utrecht University School of Economics.

Brigham, E. F. (2002). Fundamental of Financial Management, 6th Edition. Forth Worth: Dryden Press.

Chawla, D., \& Sondhi, N. (2016). Research Methodology: Concepts and Cases, 2nd edition. New Delhi: Vikas.

Dickinson, G. (2001). Enterprises risk management: its origins and conecptual foundation. The Geneva Papers of Risk and Insurance, 26(3),360-366.

Dess, G. G., \& Robinson, J. B. (1984). Measuring organizational performance in the absence of objective measures:the case of the privately-held firm and conglomerate business unit. Strategic Management Journal, 5(3), 265-273.

Falkner, E., \& Hiebl, M. R. (2015). Risk management in SMEs: a systematic review of available evidence. The Journal of Risk Finance, 16(2), 122144.

Gavrea, C., Llies, L., \& Stegerean, R. ( 201011 ). Determinants of organizational performance: the case of Romania. Management and Marketing Challenges for the Knowledge Society,6(2), 285-300.

Gwangwava, E., Manuere, F., Kudakwashe, G., Tough, C., \& Rangarirai, F. (2014). An assessment of risk management practices in SMEs in Zimbabwe:A review and synthesis. IOSR Journal of Humanities and Social Science,19(8), 06-14.

Head, G. (2009). Risk Management-Why and How. An Illustrative Introduction to Risk Management for Business Executives. Dallas Texas: International Risk Management Institute.

Henschel, T. (2009). Risk Management Practices of SMEs: Evaluating and Implementing Effective Risk Management Systems. Berlin: Enrich Schmit Verlag GMBH \& Co.

Hormiga, E., \& Bolivar-Cruz, A. (2014). The relationship between the migration experience and risk perception: a factor in the decision to become an entrepreneur. International Entrepreneurship and Management Journal,10(2), 297-317.

Idemobi, E. I. (2012). The problem of sustaining the growth of small and 
medium enterprises in a typical subsaharan African context. African Journal of Social Sciences, 2, 15-24.

Jayasekara, J. D., \& Thilakarathne, A. (2013). Government Policy and Strategy for SME Development. Ministry of Finance and Planning.

Jayathilake, P. B. (2012). Risk management practices in small and medium enterprises: evidence from Sri Lanka. International Journal of Multidisciplinary Research,2(7), 226234.

Kagawathi, G. S., Kamau, J. N., Njau, M. M., \& Kamau, S. M. (2014). Risks faced and mitigation strategies emploued by samall and medium enterprises in Nairobi, Kenya. IOSR Journal of Business Management,16(4), 01-11.

Kalegama, S. E. (2002). White Paper. Ministry of Enterprise Dvelopment.

Labodova, A. (2004). Implementing integrated management systems usinga a risk analysis based approach. Journal of Cleaner Production,12, 571-580.

Lechner, C., \& Gudmundsson, S. V. (2014). Entrepreneurial orientation, firm strategy and small frim performance. International Small Business Journal,32(1), 36-60.

Luper, I., \& Isaac, K. M. (2012). An assessment of risk management of small and medium scale enterprises in Nigeria. Research Journal of Finance and Accounting,3(5), 151-158.

Mansor, N., Yahaya, S. N., \& Okazaki, K. (2016). Risk factors affecting new product development (NPD) performance in small medium enterprises. IJRRAS, 127(1), 18-25.

Naldi, L., Nordqvist, M., Sjoberg, K., \&
Wiklund, J. (2007). Entrepreneurial orientation, risk taking, and performance in family firms. Family Business Review, 20(1), 33-47.

Ntlhane, K. E. (1995). The Application of Risk Management Principles to Smaller Enterprises (Unpublished doctoral dessertation) university of the Witwatersrand.

Rathnasiri, U. H. (2015). The financial management practices of small and medium enterprises in Sri Lanka. Global Journal of Contemporary Research in Accounting, Auditing and Business Ethics, 1(2), 374-399.

Robinson, A. T., \& Marino, L. D. (2013). Overconfidence and risk perception: do they really matter for venture creation decisions? International Entrepreneurship and Management Journal,11(1), 149-168.

Sitkin, S., \& Pablo, A. (1992). Reconceptualizing the determinants of risk behaviour. The Academy Management Review, 17(1),9-38.

Smit, Y., \& Watkins, J.A. (2012). A literature review of small and medium enterprices (SME) risk management practices in South Africa. African Journal of Business Management,6(21), 6324-6330.

Smith, T. M., \& Reece, J. S. (1999). The relationship of strategy, fit, productivity, and business performance in a services setting. Journal of Operations Management,17(2), 145-161.

Sparrow, J. (1999). Using qualitative research to established SME support needs. Qualitative Market Research,2(2), 121-134.

Tang, J., \& Tang, Z. (2007). The relationship of achievement motivation and risk- 
taking propensity to new venture performance: a test of the moderating effect of entrepreneurial munificence. International Journal of Entrepreneurship and Small Business,4(4), 450-472.

Tang, Z., Kreiser, P. M., Marino, L., \& Weaver, K. M. (2010). Exploring proactiveness as a moderator in the process of perceiving industrial munificence: a field study of SMEs in four countries. Journal of Small Business Management,48(2), 97-115.

Thapa, A. (2015). Determinants of microenterprise performance in Nepal. Small Business Economics,45(3), 581-594.

Thrikawala, S. S. (2011). Impact of strategic networks for the success of SMEs in Sri Lanka. World Journal of Social Sciences,1(2), 108-119.

Turpin, M. (2002). Risk Management in Europe: an Investigation of Medium Sized Enterprises. Mc Lennan Company.

Vaughan, E., \& Vaughan, T. (2001). Essentials of Risk Management and Insurance. New York: John Willey and Sons.

Wall, T. D., Michie, J., Patterson, M., Wood,
S. J., Sheehan, M., Clegg, C. W., \& West, M. (2004). On the validity of subjective measures of company performance. Personnel Psychology,57(1), 95-118.

Watt, J. (2007). Strategic risk management for small businesses. In Reuvid, J. (Ed.), Managing Business Risk 2nd Edition-A Practical Guide to Protecting Your Business. London: Philadelphia.

Willebrands, D., Lammers, J., \& Hartog, J. (2012). A successful businessman is not a gambler: risk attitude and business performance among small enterprises in Nigeria. Journal of Economic Psychology,33(2), 342354.

Yusuf, T. O., \& Dansu, F. S. (2013). SMEs, business risks and sustainability in Nigeria. European Journal of Business and Social Sciences,2(9), 7694.

Zulkiffli, S. A., \& Perera, N. (2011). A literature analysis on business performance for SMEs-subjective or objective measures. SIBR Conference on Interdisciplinary Business and Economics Research,1-9. Bangkok: Society of interdisciplinary business research.

\section{Appendix 1: A checklist to assess the level of risk management of SMEs}

First decide applicability of a criterion by indicating "Yes" or "No". Then decide satisfactory level of applying those practices by ticking $(\sqrt{ })$ the appropriate number according to given scale

\begin{tabular}{|c|c|c|c|c|}
\hline Highly dissatisfactory & dissatisfactory & Moderate & satisfactory & Highly satisfactory \\
\hline 1 & 2 & 3 & 4 & 5 \\
\hline
\end{tabular}




\begin{tabular}{|c|c|c|c|c|c|c|}
\hline \multirow{2}{*}{ Criteria to Assess Risk Management } & \multirow[t]{2}{*}{ Yes/No } & \multicolumn{5}{|c|}{ If "Yes" } \\
\hline & & 1 & 2 & 3 & 4 & 5 \\
\hline Risk Identification: & & & & & & \\
\hline $\begin{array}{l}\text { Do you use qualified employees to identify risks in your } \\
\text { business organization? }\end{array}$ & & & & & & \\
\hline $\begin{array}{l}\text { Do you employ external experts to identify risks in your } \\
\text { business organization? }\end{array}$ & & & & & & \\
\hline Do you prepare written reports on identified risks? & & & & & & \\
\hline $\begin{array}{l}\text { Do you seek professional advices as needed to handle } \\
\text { risks in your business organization? }\end{array}$ & & & & & & \\
\hline Risk Evaluation: & & & & & & \\
\hline $\begin{array}{l}\text { Do you conduct programs to survey your customers for } \\
\text { their satisfaction with the products and services? }\end{array}$ & & & & & & \\
\hline $\begin{array}{l}\text { Do you operate your business according to a strict } \\
\text { business plan? }\end{array}$ & & & & & & \\
\hline $\begin{array}{l}\text { Do you implement risk-assessment programs to identify } \\
\text { future risks? }\end{array}$ & & & & & & \\
\hline
\end{tabular}

\begin{tabular}{|l|l|l|l|l|l|}
\hline Risk Mitigation: & & & & & \\
\hline $\begin{array}{l}\text { Do you maintain establish risk- assessment programs at } \\
\text { satisfactory level? }\end{array}$ & & & & & \\
\hline $\begin{array}{l}\text { Do you enter in to formal business agreements with your } \\
\text { suppliers? }\end{array}$ & & & & & \\
\hline $\begin{array}{l}\text { Do you enter in to formal business agreements with your } \\
\text { customers? }\end{array}$ & & & & \\
\hline $\begin{array}{l}\text { Do you intend to obtain insurance policies to cover assets } \\
\text { in your business organization? }\end{array}$ & & & & & \\
\hline Risk Monitoring: & & & & & \\
\hline Do you define objectives of your business clearly? & & & & & \\
\hline $\begin{array}{l}\text { Do you use checklists to prevent errors in your business } \\
\text { organization? }\end{array}$ & & & & & \\
\hline $\begin{array}{l}\text { Do You prepare management accounting reports and make } \\
\text { decisions to control production cost? }\end{array}$ & & & & & \\
\hline $\begin{array}{l}\text { Do you employ outsiders to monitor establish internal } \\
\text { controls? }\end{array}$ & & & & & \\
\hline
\end{tabular}

